
\title{
3 Research Square \\ Determinants of Food Safety Knowledge among University Students in Pakistan: A Cross-Sectional Study
}

\section{Azmat Ullah}

University of veterinary \& Animal Sciences Lahore

\section{Waqas Ahmad}

University of Veterinary and Animal Sciences Lahore

\section{Farhan Saeed}

Government College University Faisalabad

\section{Muhammad Sohaib}

College of Veterinary and Animal Science Bikaner

\section{Hafiz Muhammad Shahbaz}

University of Veterinary and Animal Sciences Lahore

\section{Muhammad Sajid Arshad}

Government College University Faisalabad

\section{Faqir M Anjum ( $\nabla$ dranjum@utg.edu.gm )}

University of the Gambia

\section{Research article}

Keywords: food safety knowledge, food hygiene knowledge, foodborne illness, food handling practice, university students

Posted Date: September 11th, 2020

DOl: https://doi.org/10.21203/rs.3.rs-35350/v2

License: (c) (1) This work is licensed under a Creative Commons Attribution 4.0 International License. Read Full License 


\section{Abstract}

Background Foodborne diseases are among the most serious public health problems and young adults are an important target group as they often engage in risky food handling practices. The purpose of this study was to assess the level of food safety knowledge and its determinants among Pakistani university students. Method A cross-sectional study was conducted among university students during the academic year 2018-2019. A convenient sample of 1417 students completed a structured questionnaire containing forty-four questions on food safety and hygiene. Results Overall, participants showed a moderate level of food safety knowledge with a mean percentage score of $62.5 \pm 8.4$. Students had a good level of knowledge about causes of foodborne diseases $(66.3 \pm 16.9)$. However, the lowest level of knowledge was identified in foodborne diseases' symptoms (55.2 \pm 14.3$)$. In general, females and participants from health-related degree program scored significantly higher $(p<0.01)$ in all knowledge sections than their counterparts. A significant association was found between the causes of foodborne diseases and postgraduate students being more knowledgeable $(p<0.001)$. Multivariate logistic regression analysis showed that age, gender, academic degree program, level of education, and father's education were significant predictors of overall food safety knowledge. Conclusion The results of this study showed that university students have a moderate knowledge in food safety. Educational interventions and awareness programs are needed to strengthen the existing knowledge.

\section{Background}

Food safety is one of the leading concerns being challenged not only in developed countries but is equally a threat to developing countries (Godfray et al. 2010). Besides, food safety holds to be an important aspect in public health and epidemiology as it is directly related to worldwide food-borne illness and diseases (Kadariya et al. 2014). Additionally, as per Global Burden of Disease, it is envisaged that millions of humans are subject to food-borne illness largely governed by poor hygiene and food handling practices (Kirk et al. 2015).

It has been learned that food-borne diseases from contaminated food is responsible for millions of deaths globally with billions of dollars being spent on health care costs and hospitalization annually (Hoffmann and Scallan 2017). Nevertheless, the World Health Organization [WHO] routinely identifies upsurges food-borne disease outbreaks and epidemics that are point of interest for public health specialists, epidemiologists and health professionals. Even in the most developed food supply chain regions as European Union and United States, still there are reports of product recall, associated disease and illness issues (Newell et al. 2010). According to United States FDA statistics 2017, nearly 23\% of the processed foods in United States had been recalled due to potential risk linked to public health epidemic and food safety concerns. However, for developing countries there is no such reliable data exists even that can portray a glooming snapshot of food safety (Pearson-Stuttard et al. 2018).

Ingested food can become a source of disease if ingredients storage, handling, preparation, processing and product storage are not followed properly. In this context, consumer knowledge, awareness and 
attitude are perhaps the pillars predicting the overall food safety stratum as consumer behavior is largely governed by the existing food handling procedures, food safety knowledge and general hygiene following the postulates of Theory of Planned Behaviour (Vecchione et al. 2015).

According to World Health Organization, "food safety is a scientific discipline describing handling, preparation and storage of food in order to avoid food-borne illness. That food safety procedure includes variety of practices needed to be followed to prevent the entry of potential health hazard responsible for the diseases". Furthermore, microorganisms are reported as major food safety hazard as they compete for nutrients with humans for their growth and survival (Callejón et al. 2015). Hence, the significance of food safety and hygiene is of paramount importance as being a vital component of food supply chain, thereby assuring consumer confidence and safety (Callejón et al. 2015). In this milieu, contaminated raw food, inadequate cooking, and consumption of food from an unsafe source are principal factors often associated with food-borne diseases in homes, restaurants and vendor foods (Smigic et al. 2016). Accordingly, public health and its significance cannot be ignored and is totally concerned with food safety attitudes, knowledge and handling practices of food processors. As far as the global statistics are concerned, knowledge and awareness rankings for both the developed and developing countries are not so encouraging. Furthermore, developing countries are much behind others when it comes to food safety knowledge and awareness (Arocena et al. 2015).

Lahore, the capital of the Punjab province, is the second largest metropolitan city of Pakistan with a population above 15 million individuals. In such a populated city, the significance of food safety becomes manifold when survival, well-being and health of individuals cannot be held at stake. Besides, health of school/college and university going students is at risk due to the consumption of unsafe/unhygienic food being supplied, processed and sold in school or university canteens and eateries. Furthermore, general food safety is quite blissful reasoned to lack of awareness, education and rather weak legislation. More recently, dedicated efforts have been made on strengthening existing food safety legislation that includes revision of pure food rules and extending additional powers to officials related to food inspection and regulation. Nevertheless, still a lot more work needs to be done.

Keeping the severity of existing food safety issue, the present research was conducted to assess the level of food safety knowledge and to investigate the association between the food safety knowledge and the socio-demographic and academic characteristics among university students/youth in Lahore.

\section{Methods}

\section{Study design and population}

A cross-sectional study was conducted from September 2019 to December 2019 to assess food safety knowledge and its determinants among university students. The study employed a multistage sampling technique. This was done in consideration that the Pakistani university system has been classified into two categories: Public university, and private university. 
During the first stage, we randomly selected two public and two private universities (Universities of Veterinary and Animal Science, University of Punjab, University of Lahore, University of Management technology and Government College University Lahore). The second stage involved the random selection of students who participated in the study. To ensure a representative sample of each university, students were recruited according to the proportions of students in each university, based on the Higher Education Commission data (Ref).

The purpose and details of the study were explained in detail to participants in simple and clear language and voluntary written consent obtained. A total of 1500 students were randomly approached in selected universities and invited to participate in the study. Of those approached, 1417 (94.5\%) consented and completed the survey. Participant were stratified into two fields of studies; health-related disciplines and non-health related disciplines. Where possible we followed the STROBE (Strengthening the Reporting of Observational studies in Epidemiology) guidelines (Von Elm et al. 2007) (Additional file 1).

\section{Instrumentation}

In order to assess the food safety knowledge of students, a 44-item structured questionnaire was designed by reviewing relevant literature and previously used standardized, validated questionnaires (Byrd-Bredbenner et al. 2007; Norazmir et al. 2012; Patah et al. 2009; Thompson et al. 2007; Walker et al. 2003). Where necessary, modifications were made in the questionnaire to meet the local needs. Before data collection, the questionnaire was pilot tested with 50 students for clarity and acceptability. These respondents were not included in the study. This pilot study resulted in minor modifications in the questionnaire, including rephrasing of a few questions and terminology. The final questionnaire was divided into five sections. The first of which collected personal information (5 questions), such as their age, gender, level of education, academic discipline and parents' education. The second section included 11 specific questions to test knowledge on personal hygiene. The third section of questionnaire (9 items) aimed to investigate the knowledge of students on causes of food-borne diseases. Questions in the fourth section (12 items) were related to recognizing the common symptoms of food-borne diseases. The last section of the questionnaire (12 items) aimed to assess the knowledge of food handling practices.

The questions regarding food safety knowledge were graded as true and false. For each question, "1" was given to the correct answer and "0" was given to the incorrect answer. Good knowledge was defined if question exploring food safety knowledge was answered correctly by more than $50 \%$ of participants. After taking the ethical approval initially from the Ethical Review Board of the University of Veterinary and Animal Sciences, a questionnaire was approved by respective institutional review boards of participant universities.

\section{Statistical Analysis}

The data collected were analyzed using Statistical Package for the Social Sciences (SPSS version 20.0). The response was entered as a categorical variable, right answer was assigned the score of 1 point whereas, 0 point was assigned to all wrong answers. Higher knowledge scores indicate greater 
knowledge. For each knowledge section, the mean score was calculated and converted into percentage. Descriptive statistics were carried out to summarize demographic characteristics and data regarding food safety knowledge. Comparison of food safety knowledge between different demographic variables was performed using $t$-test and analysis of variance (ANOVA). For logistic regression model, food safety knowledge score was dichotomized into high and low scoring groups according to the median of each subsection. For all statistical comparisons, a p-value of $\leq 0.05$ was considered significant.

\section{Results}

\section{Backgrounds data}

A total of 1417 questionnaire forms were filled by university students. Distribution of demographic characteristics of the study population is presented in Table 1 . Of the participants, $68 \%$ were female participants and $32 \%$ male with a mean age of 22 years ( \pm standard deviation (SD) \pm 2.9 ). The data shows that the majority of the participants $(62.8 \%)$ were in the age group of $20-24$ years and $79.8 \%$ of them were undergraduate students. The students comprised of two educational groups; $41.8 \%$ from health-related and $58.2 \%$ from non-health related majors. Majority of the respondents' fathers had university education and mothers had college education.

\section{Overall food safety knowledge score}

Table 2 presents the mean scores of knowledge sections and overall food safety knowledge. Results showed that the respondents had a moderate knowledge about overall food safety with a mean score of $62.48 \%$. Participants achieved the highest score for the knowledge on causes of food-borne diseases (66.25\%) and the lowest score for the knowledge on food handling practices (63.77\%).

Table 3 showed the percentages of correct responses for the questions about personal hygiene practices. Majority of the respondents answered correctly for all questions except the question 4, 6 and 7 for which students had lowest percentage of correct answers. Only 35.3\% gave the correct answer for question "It is not safe to store chicken, fish and raw meat together in a fridge or freezer", $88 \%$ wrongly believed that "To avoid food poisoning, you should clean the kitchen sink drain every week" and $16.2 \%$ did know the correct answer for the question "The best way to avoid food poisoning from fruits and vegetables is to wash them under a running tap".

Descriptive results of knowledge questionnaire in the area of food-borne diseases are presented in Table 4. Respondents had poor knowledge (28.8\%) about the consumption of canned vegetable and they believe that its consummation without prior heating will increase one's risk of suffering food poisoning. About $30.8 \%$ of the students gave wrong answer to the question about the "Leftover chicken eaten cold can cause food-borne diseases".

This study found that students had least knowledge about the symptoms of food-borne diseases. Majority of the respondents didn't know that body temperature rises quickly $(79 \%)$, low blood pressure 
(64.7\%), sweats (66.8\%), pain in the bone (52.7\%), coughing or sneezing (64\%) are not the symptoms of food-borne diseases. Only $45.9 \%$ students correctly know that stiff neck is also a symptom of the foodborne diseases (Table 5)

Improper food handling practices are thought to contribute to a high number of food-borne illness outbreaks. Data presented in table 6 show the respondents knowledge on food handling practices. Most of the participants (86\%) failed to select the correct answer for the question about "Thorough washing of vegetables and fruits in tap water is necessary to prevent food poisoning". Likewise, only $17.1 \%$ and $38.4 \%$ of the correspondents knew that the food handler should be medically examined every six months and they cannot clean their hands by wiping them on a piece of cloth, respectively. Over half of the respondents $(53.7 \%)$ believed that it is unnecessary to reheat the previously cooked food.

\section{Impact of socio-demographic characteristics on students' food safety knowledge}

Students aged above 30-year had significantly lower knowledge on all the types of knowledge scores except "symptoms of food-borne diseases" where the score was lower, but the result was non-significant. There was a statistically significant difference between the gender and the knowledge on personal hygiene practices, causes of food-borne diseases, symptoms of food-borne diseases, food handling practice and overall knowledge. Female students showed significantly higher score $(63.1 \pm 8.2)$ on all the types of knowledge (Table 7).

Current levels of education of students had no effect on all the types of knowledge scores except the causes of food-borne diseases. Postgraduate students had significantly higher scores for causes of foodborne diseases than undergraduate students. The mean score of all knowledge types of health science students was higher than non-health related students and the difference between means was statistically significant (Table 7).

According to this study, students whose fathers were educated had significantly higher mean knowledge of all groups except personal hygienic practices. Participants whose mother was educated had significantly higher mean score on overall knowledge and knowledge on symptoms of food-borne diseases.

\section{Predictors of food safety knowledge}

Multivariate logistic regression analysis was used to explore the significant predictors among the sociodemographic variables for food safety knowledge. As shown in Table 8, regression analysis showed that age, gender, education level, academic discipline and father's education are significantly $(P<0.05)$ associated with overall food safety knowledge. In the full model, being female (OR $=1.88, P=0.001)$, postgraduate students $(\mathrm{OR}=1.28, P=0.001)$, students from health-related majors $(\mathrm{OR}=3.84, P=0.001)$ and students who had educated father $(\mathrm{OR}=3.87, P=0.001)$ were positively associated with adequate food safety knowledge. A negative association was also found between age groups higher than 30 years and overall food safety knowledge $(O R=0.09, P=0.001)$. For personal hygiene practices knowledge, age 
group 20-24 (OR $=1.82, P=0.001), 25-29$ years $(\mathrm{OR}=2.05, P=0.017)$, health-related majors $(\mathrm{OR}=3.16, P$ $=0.001)$ and father's education $(\mathrm{OR}=2.21, P=0.029)$ were positively associated with adequate knowledge. In addition, female gender $(\mathrm{OR}=0.67, P=0.004)$, being in age group of $>30$ years $(\mathrm{OR}=0.34$, $P=0.040)$ and having higher education ( $O R=0.62, P=0.004)$ were negatively associated to the personal hygiene practices knowledge. As for the knowledge on causes of foodborne diseases, being in age group 20-24 (OR $=1.31, P=0.037)$ and 25-29 years $(\mathrm{OR}=2.07, P=0.021)$, female gender $(\mathrm{OR}=10.268, P=$ $0.064)$, having higher education $(\mathrm{OR}=1.421, P=0.035)$, health-related majors $(\mathrm{OR}=2.057, P=0.001)$ and father's education $(\mathrm{OR}=3.340, P=0.001)$ were positively associated with adequate knowledge. In addition, being in age 25-29 years $(O R=2.07, P=0.021)$, female gender $(O R=10.268, P=0.064)$, healthrelated majors $(\mathrm{OR}=2.057, P=0.001)$ and educated father $(\mathrm{OR}=3.340, P=0.001)$ were positively associated with adequate knowledge on symptoms of foodborne diseases. The subjects in age groups above 30 years with a high education level were more likely to have inadequate knowledge on symptoms of foodborne diseases. Age group 20-24 (OR = 0.72, $P=0.010)$ and mother's education $(\mathrm{OR}=039, P=$ 0.001 ) revealed a negative relationship with knowledge on of foodborne diseases.

\section{Discussion}

To date, there is no study documenting food safety knowledge status among the Pakistani consumers. This investigation provides valuable information about the self-reported food safety knowledge of young adults enrolled in different universities of Lahore city. It has been previously reported that poor hygiene knowledge and practices of consumers are associated with $87 \%$ of reported food-borne outbreaks linked to food prepared or consumed in private homes in the United Kingdom, Europe, Australia, New Zealand, the United States, and Canada (Redmond and Griffith 2003). Therefore, it is important to educate the consumers about safe food handling and preparation (Gurudasani \& Sheth, 2009).

In general, overall participants' responses revealed optimal levels of food safety knowledge with a mean score of $62.48 \%$. The moderate level of food safety knowledge among the students was also a common finding in a previous similar study aimed at evaluating determinants of food hygiene knowledge among University students of Malaysia and Saudi Arabia, respectively. (Low et al. 2016; Sharif and Al-Malki 2010). On the other hand, several studies identified a better food safety knowledge among participants as compared to our findings, reasoned to better exposure, prior food safety knowledge and geographical location [as mostly such results have been attained in developed countries] (Abbot et al. 2009; ByrdBredbenner et al. 2007; Lazou et al. 2012; Sharif and Al-Malki 2010).

Four different sets of questions were designed to access food safety knowledge, the participants exhibited slightly low knowledge on symptoms of food-borne diseases (mean score of $55.18 \%$ ). Similarly, a previous study in Kuala Lumpur city observed that participants had the lowest knowledge score on symptoms of food-borne diseases (Low et al. 2016).

Although some studies reported that food safety knowledge score significantly increases with age (ByrdBredbenner et al. 2007; Low et al. 2016; Osaili et al. 2011; Sharif and Al-Malki 2010; Unklesbay et al. 
1998), might be due to extended exposure and education. Nevertheless, in our findings, this pattern was not observed as some younger students depicted a rather higher level of food safety knowledge that may be linked to improved food safety knowledge. This finding is consistent with the results of (Unklesbay et al. 1998), who suggested that the young population have more access to TV and social media and, therefore, higher opportunities of knowledge sharing. In all four types of food safety knowledge sections, female students obtained significantly higher scores than males. Female students significantly outperformed males on all four types of food safety knowledge. These findings are comparable with the previous researches conducted in USA, Greece and Turkey, where females have higher food safety knowledge scores than males (Byrd-Bredbenner et al. 2007; Lazou et al. 2012; Sanlier 2009; Unklesbay et al. 1998). In Pakistani culture, in any household, females are responsible for the food preparation and cooking; that could be the reason of their high food safety knowledge score.

Students in health-related disciplines reported significantly higher food safety knowledge scores than non-health related students since they are expected to learn basic food safety elements in the syllabi at the elementary and intermediate levels. The present finding is consistent with previous investigations conducted in Jordan, Saudi Arabia and USA (Byrd-Bredbenner et al. 2007; Morrone and Rathbun 2003; Osaili et al. 2011; Sharif and Al-Malki 2010; Unklesbay et al. 1998) where the students from an academic discipline related to health sciences had more knowledge on food safety. According to this study, the father's education rather than the mother's education is positively associated with the level of healthrelated knowledge of college students. Fathers may play an important role in delivering food safety knowledge to their children. Our findings agree with (Low et al. 2016), who found that father's education influenced the food safety score of their children. Furthermore, multivariate logistic regression models revealed significant relationships between all four types of food safety knowledge groups and all independent variables (age, educational level, academic discipline, father's education) except mother's education.

\section{Conclusion}

In conclusion, this study suggest the need for educational strategies at various levels to improve the current food safety awareness, especially for the sake of their future roles as caregivers for their families. Educating people about the basic principles of food safety hygiene could significantly affect the number of food-borne illnesses and leads towards better public health protection. There is a strong consensus among international experts that food safety programs should be integrated into the usual school curriculum to increase awareness. Furthermore, a university setting would also be a promising place to reach and educate the young adults with key food safety concepts as they are the future cooks, chefs, food handlers and homemakers. The university curriculum could also emerge as an ideal setting to provide food safety knowledge across all the disciplines regardless of food, nutrition and health background.

\section{Limitation of the study}


The current study has also some limitations. This study focused on the university students Lahore city, Pakistan therefore, it is unlikely to be generalizable. The study measured self-reported knowledge, which may risk recall bias and cultural factors.

\section{Abbreviations}

WHO: World Health Organization; SD: Standard Deviation; ANOVA: Analysis of Variance; SPSS: Statistical Package for the Social Sciences; OR: Odd Ratio

\section{Declarations}

\section{Ethics approval and consent to participate}

This study was reviewed and received ethics clearance through a University of Veterinary and Animal Sciences, Lahore Research Ethics Committee. Study participants were briefed on the purpose of the study, and written informed consent was obtained.

\section{Consent to publish}

Consent for publication was obtained from all authors.

\section{Availability of data and material}

The authors declare that the data supporting the findings of this study are fully described within the manuscript. Raw data supporting this study may be made available upon request

to the corresponding author.

\section{Competing interests}

The authors declare that they have no competing interests.

\section{Funding}

No funding sources.

\section{Authors' contributions}

AU and FMA conceived and designed the study, and AU, WA, FS collected the data. HMS and MSA conceived the analysis plan. AU interpreted the results with input from WA and MS. All authors provided comments on drafts, and read and approved the final manuscript.

\section{Acknowledgments}


The authors would like to thank the student community whose voluntarily participation has made this study possible.

\section{References}

Abbot JM, Byrd-Bredbenner C, Schaffner D, Bruhn C, Blalock L. 2009. Comparison of food safety cognitions and self-reported food-handling behaviors with observed food safety behaviors of young adults. Eur J Clin Nutr. 63(4): 572.

Arocena R, Göransson B, Sutz J. 2015. Knowledge policies and universities in developing countries: Inclusive development and the "developmental university". Technology in Society. 41: 10-20.

Byrd-Bredbenner C, Maurer J, Wheatley V, Schaffner D, Bruhn C, Blalock L. 2007. Food safety self-reported behaviors and cognitions of young adults: results of a national study. Journal of Food Protection. 70(8): 1917-1926.

Callejón RM, Rodríguez-Naranjo MI, Ubeda C, Hornedo-Ortega R, Garcia-Parrilla MC, Troncoso AM. 2015. Reported foodborne outbreaks due to fresh produce in the United States and European Union: trends and causes. Foodborne Pathog Dis. 12(1): 32-38.

Godfray HCJ, Beddington JR, Crute IR, Haddad L, Lawrence D, Muir JF, Pretty J, Robinson S, Thomas SM, Toulmin C. 2010. Food security: the challenge of feeding 9 billion people. Science. 327(5967): 812-818.

Hoffmann S, Scallan E. 2017. Epidemiology, Cost, and Risk Analysis of Foodborne Disease. In: Dodd CE, Aldsworth TG, Stein RA, editors. Foodborne Diseases 3rd ed. London Elsevier. p. 31-63.

Kadariya J, Smith TC, Thapaliya D. 2014. Staphylococcus aureus and staphylococcal food-borne disease: an ongoing challenge in public health. Biomed Res Int. 2014.

Kirk MD, Pires SM, Black RE, Caipo M, Crump JA, Devleesschauwer B, Döpfer D, Fazil A, Fischer-Walker CL, Hald T. 2015. World Health Organization estimates of the global and regional disease burden of 22 foodborne bacterial, protozoal, and viral diseases, 2010: a data synthesis. PLoS Med. 12(12): e1001921.

Lazou T, Georgiadis M, Pentieva K, McKevitt A, lossifidou E. 2012. Food safety knowledge and foodhandling practices of Greek university students: A questionnaire-based survey. Food Control. 28(2): 400411.

Low WY, Jani R, Halim HA, Alias AA, Moy FM. 2016. Determinants of food hygiene knowledge among youths: a cross-sectional online study. Food Control. 59: 88-93.

Morrone M, Rathbun A. 2003. Health education and food safety behavior in the university setting. $J$ Environ Health. 65(7): 9. 
Newell DG, Koopmans M, Verhoef L, Duizer E, Aidara-Kane A, Sprong H, Opsteegh M, Langelaar M, Threfall J, Scheutz F. 2010. Food-borne diseases-the challenges of 20 years ago still persist while new ones continue to emerge. Int J Food Microbiol. 139: S3-S15.

Norazmir M, Hasyimah N, Siti Shafurah A, Siti Sabariah B, Ajau D, Hazali N. 2012. Knowledge and practices on food safety among secondary school students in Johor Bahru, Johor, Malaysia. Pakistan J Nutr. 11(2): 110-115.

Osaili TM, Obeidat BA, Jamous DOA, Bawadi HA. 2011. Food safety knowledge and practices among college female students in north of Jordan. Food Control. 22(2): 269-276.

Patah MORA, Issa ZM, Nor KM. 2009. Food Safety Attitude of Culinary Arts Based Students in Public and Private Higher Learning Institutions (IPT). Int EducStud. 2(4): 168-178.

Pearson-Stuttard J, Kypridemos C, Collins B, Mozaffarian D, Huang Y, Bandosz P, Capewell S, Whitsel L, Wilde P, O'Flaherty M. 2018. Estimating the health and economic effects of the proposed US Food and Drug Administration voluntary sodium reformulation: Microsimulation cost-effectiveness analysis. PLoS Med. 15(4): e1002551.

Redmond EC, Griffith CJ. 2003. Consumer food handling in the home: a review of food safety studies. $J$ Food Prot. 66(1): 130-161.

Sanlier N. 2009. The knowledge and practice of food safety by young and adult consumers. Food Control. 20(6): 538-542.

Sharif L, Al-Malki T. 2010. Knowledge, attitude and practice of Taif University students on food poisoning. Food Control. 21(1): 55-60.

Smigic N, Djekic I, Martins ML, Rocha A, Sidiropoulou N, Kalogianni EP. 2016. The level of food safety knowledge in food establishments in three European countries. Food Control. 63: 187-194.

Thompson B, Ribera K, Wingenbach G, Vestal T. 2007. The relationship between attitudes, knowledge, and demographic variables of high school teachers regarding food irradiation. J Food Sci Educ. 6(2): 24-29.

Unklesbay N, Sneed J, Toma R. 1998. College students' attitudes, practices, and knowledge of food safety. J Food Prot. 61(9): 1175-1180.

Vecchione M, Feldman C, Wunderlich S. 2015. Consumer knowledge and attitudes about genetically modified food products and labelling policy. International journal of food sciences and nutrition. 66(3): 329-335.

Von Elm E, Altman DG, Egger M, Pocock SJ, Gøtzsche PC, Vandenbroucke JP. 2007. The Strengthening the Reporting of Observational Studies in Epidemiology (STROBE) statement: guidelines for reporting observational studies. Ann Intern Med. 147(8): 573-577. 
Walker E, Pritchard C, Forsythe S. 2003. Food handlers' hygiene knowledge in small food businesses.

Food Control. 14(5): 339-343.

\section{Tables}

Table 1-Socio-demographic characteristics of the study population comprising university students.

\begin{tabular}{|c|c|c|}
\hline Socio-demographic characteristics & Participants (n) & Percentage (\%) \\
\hline \multicolumn{3}{|l|}{ Age group (years) } \\
\hline $18-19$ & 426 & 30.1 \\
\hline $20-24$ & 890 & 62.8 \\
\hline $25-29$ & 80 & 5.6 \\
\hline$\geq 30$ & 21 & 1.5 \\
\hline \multicolumn{3}{|l|}{ Gender } \\
\hline Male & 453 & 32.0 \\
\hline Female & 964 & 68.0 \\
\hline \multicolumn{3}{|l|}{ Level of education } \\
\hline Undergraduate & 1131 & 79.8 \\
\hline Postgraduate & 286 & 20.2 \\
\hline \multicolumn{3}{|l|}{ Academic discipline } \\
\hline Non-health related & 825 & 58.2 \\
\hline Health related & 592 & 41.8 \\
\hline \multicolumn{3}{|l|}{ Father's education } \\
\hline Uneducated & 52 & 3.7 \\
\hline Educated & 1365 & 96.3 \\
\hline \multicolumn{3}{|l|}{ Mother's education } \\
\hline Uneducated & 103 & 7.3 \\
\hline Educated & 1314 & 92.7 \\
\hline
\end{tabular}

Health related disciplines include those students who had sufficient prior knowledge about basic food safety and factors affecting consumer health. Whereas, non-health related disciplines mainly include students from fine arts and management sciences who have comparatively lesser knowledge about food safety and hygiene as compared to their counter parts.

Table 2-Mean score of food safety knowledge of the study population comprising university students. 


\begin{tabular}{lcccc}
\hline Type of knowledge & Min. & Max. & Mean & Std. deviation \\
\hline Personal hygiene practices & 27.3 & 90.9 & 64.8 & 11.5 \\
Causes of foodborne diseases & 11.2 & 100.0 & 66.3 & 16.9 \\
Symptoms of foodborne diseases & 0.00 & 91.0 & 55.2 & 14.3 \\
Food handling practice & 0.00 & 91.7 & 63.8 & 13.9 \\
Overall Score & 29.9 & 91.7 & 62.5 & 8.4 \\
\hline
\end{tabular}

Table 3-Assessment of knowledge on personal hygiene practices.

\begin{tabular}{|c|c|c|c|c|}
\hline No & Statements & $\begin{array}{l}\text { Correct } \\
\text { answer }\end{array}$ & $\mathrm{n}^{\mathrm{a}}$ & $\%$ \\
\hline 1 & Take care of personal hygiene ensures safe food & Yes & 1361 & 96.0 \\
\hline 2 & Pasteurization of beverages helps to prevent food-borne disease & Yes & 1251 & 88.3 \\
\hline 3 & Always wash hands after coughing or sneezing & Yes & 1275 & 90.0 \\
\hline 4 & To avoid food poisoning, you should clean the kitchen sink drain every week & No & 170 & 12.0 \\
\hline 5 & Physical hazards (hair) can cause illness & Yes & 1034 & 73.0 \\
\hline 6 & It is not safe to store chicken, fish and raw meat together in a fridge or freezer & No & 500 & 35.3 \\
\hline 7 & $\begin{array}{l}\text { The best way to avoid food poisoning from fruits and vegetables is to wash them under a } \\
\text { running tap }\end{array}$ & No & 230 & 16.2 \\
\hline 8 & Washing hands with plain water is enough to remove microbes & No & 819 & 57.8 \\
\hline 9 & If raw foods come into contact with ready-to-eat foods, cross-contamination can occur & Yes & 1147 & 80.9 \\
\hline 10 & To determine the safety of food, you should smell it first and check the expiry date & Yes & 1268 & 89.5 \\
\hline 11 & Avoid bare hand contact with ready-to-eat food & Yes & 1024 & 72.3 \\
\hline
\end{tabular}

${ }^{\text {a }}$ Correct response and corresponding percentage

Table 4-Assessment of knowledge on causes of food-borne disease. 


\begin{tabular}{|c|c|c|c|c|}
\hline No & Statements & $\begin{array}{l}\text { Correct } \\
\text { answer }\end{array}$ & $\mathrm{n}^{\mathrm{a}}$ & $\%$ \\
\hline 1 & Consumption of raw/undercooked seafood will alleviate the risk of food poisoning & Yes & 1225 & 86.5 \\
\hline 2 & Eat canned food that has been bloated may increase the risk of food-borne disease & Yes & 1173 & 82.8 \\
\hline 3 & Storage of dry food near the oven will increase one's risk of food-borne illness & Yes & 850 & 60.0 \\
\hline 4 & Consumption of rice left overnight in the kitchen will increase the risk of food-borne disease & Yes & 981 & 69.2 \\
\hline 5 & Consumption of leftover chicken without prior heating will increase the risk of food-borne disease & No & 436 & 30.8 \\
\hline 6 & Consumption of canned food without prior heating increases the risk of food poisoning & No & 408 & 28.8 \\
\hline 7 & Consumption of food that exposed without cover will increase the risk of food-borne disease & Yes & 1166 & 82.3 \\
\hline 8 & $\begin{array}{l}\text { Consumption of chocolate cake that was left overnight in the kitchen will increase the risk of food-borne } \\
\text { disease }\end{array}$ & Yes & 1031 & 72.8 \\
\hline 9 & Salmonella bacteria can cause food-borne illness & Yes & 1140 & 80.5 \\
\hline
\end{tabular}

${ }^{a}$ Correct response and corresponding percentage

Table 5-Assessment of knowledge on symptoms of food-borne diseases.

\begin{tabular}{|c|c|c|c|c|}
\hline No & Symptoms of food borne diseases & Correct answer & $\mathrm{n}^{\mathrm{a}}$ & $\%$ \\
\hline 1 & Abdominal cramps & Yes & 1184 & 83.6 \\
\hline 2 & Pain upon moving the eyes & No & 680 & 48.0 \\
\hline 3 & Sudden increase in body temperature & No & 298 & 21.0 \\
\hline 4 & Lethargy & Yes & 1063 & 75.0 \\
\hline 5 & Headache & Yes & 1045 & 73.7 \\
\hline 6 & Blood pressure drop & No & 500 & 35.3 \\
\hline 7 & Fever & Yes & 1034 & 73.0 \\
\hline 8 & Stiff neck & Yes & 650 & 45.9 \\
\hline 9 & Diarrhea & Yes & 1190 & 84.0 \\
\hline 10 & Sweats & No & 470 & 33.2 \\
\hline 11 & Bone pain & No & 670 & 47.3 \\
\hline 12 & Coughing or sneezing & No & 510 & 36.0 \\
\hline
\end{tabular}

\footnotetext{
${ }^{\text {a }}$ Correct response and corresponding percentage
} 


\begin{tabular}{|c|c|c|c|c|}
\hline No & Statements & $\begin{array}{l}\text { Correct } \\
\text { answer }\end{array}$ & $\mathrm{n}^{\mathrm{a}}$ & $\%$ \\
\hline 1 & Smoking is not allowed in food preparation area & Yes & 1280 & 91.0 \\
\hline 2 & Each food handler should undergo medical examination every six months & No & 241 & 17.1 \\
\hline 3 & $\begin{array}{l}\text { Food handlers must wash their hands thoroughly with soap and warm running water before handling the } \\
\text { food }\end{array}$ & Yes & 1228 & 87.3 \\
\hline 4 & All surfaces that may contact the food product, should be washed and sanitized & Yes & 1120 & 79.6 \\
\hline 5 & Use separate cutting boards for fruits and meat & Yes & 1085 & 77.1 \\
\hline 6 & Store the cleaning products separately & Yes & 1247 & 88.6 \\
\hline 8 & Food handler can clean their hands with wiping cloth before cooking & No & 540 & 38.4 \\
\hline 7 & Reheating the leftovers food is unnecessary & No & 652 & 46.3 \\
\hline 9 & Thorough washing of vegetables and fruits in tap water is necessary to prevent food poisoning & No & 198 & 14.1 \\
\hline 10 & Food handler must wear clean uniform while handling or preparing food & Yes & 1135 & 80.7 \\
\hline 11 & It is not important to clean your knife after usage & No & 900 & 64.0 \\
\hline 12 & Raw food and cooked food should be stored separately in the fridge & Yes & 1201 & 85.4 \\
\hline
\end{tabular}

${ }^{a}$ Correct response and corresponding percentage

Table 7-Mean score of food safety knowledge by demographic variables. 


\begin{tabular}{|c|c|c|c|c|c|}
\hline $\begin{array}{l}\text { Demographic } \\
\text { variables }\end{array}$ & $\begin{array}{c}\text { Personal hygiene } \\
\text { practices }\end{array}$ & $\begin{array}{c}\text { Causes of food-borne } \\
\text { diseases }\end{array}$ & $\begin{array}{c}\text { Symptoms of food-borne } \\
\text { diseases }\end{array}$ & $\begin{array}{c}\text { Food handling } \\
\text { practice }\end{array}$ & $\begin{array}{c}\text { Overall } \\
\text { knowledge }\end{array}$ \\
\hline \multicolumn{6}{|l|}{ Age group (years) } \\
\hline $18-19$ & $59.4 \pm 12.8$ & $64.1 \pm 18.3$ & $55.2 \pm 12.9$ & $64.8 \pm 13.6$ & $61.9 \pm 8.8$ \\
\hline $20-24$ & $62.3 \pm 10.6$ & $66.3 \pm 16.7$ & $54.6 \pm 14.2$ & $62.8 \pm 13.7$ & $62.2 \pm 8$ \\
\hline $25-29$ & $61.3 \pm 10.3$ & $70.7 \pm 15.6$ & $57.3 \pm 11.3$ & $59.4 \pm 16.3$ & $63.2 \pm 9.7$ \\
\hline$\geq 30$ & $46.7 \pm 13.6$ & $55.6 \pm 13.6$ & $50 \pm 15.8$ & $56 \pm 17.5$ & $52.1 \pm 5.4$ \\
\hline Significance & $.000 *$ & $.001 *$ & .124 & $.001 *$ & $.001 *$ \\
\hline \multicolumn{6}{|l|}{ Gender } \\
\hline Male & $62.6 \pm 11.9$ & $63.6 \pm 17.8$ & $53.4 \pm 13.4$ & $59.5 \pm 13.9$ & $59.8 \pm 8.1$ \\
\hline Female & $65.2 \pm 11.3$ & $66.9 \pm 16.6$ & $55.6 \pm 13.7$ & $64.7 \pm 13.6$ & $63.1 \pm 8.2$ \\
\hline Significance & $.001 *$ & $.01 *$ & $.001 *$ & $.001 *$ & $.002 *$ \\
\hline \multicolumn{6}{|l|}{ Education level } \\
\hline Undergraduate & $65.1 \pm 10.8$ & $64.9 \pm 17.4$ & $55.4 \pm 14.5$ & $64.1 \pm 13.8$ & $62.6 \pm 8.3$ \\
\hline Post graduate & $66.1 \pm 11.9$ & $68.9 \pm 15.8$ & $54.7 \pm 10.3$ & $63.0 \pm 14.8$ & $62.8 \pm 8.3$ \\
\hline Significance & .570 & $.001 *$ & .766 & .624 & .876 \\
\hline \multicolumn{6}{|l|}{ Academic discipline } \\
\hline Non-health related & $61.1 \pm 12.3$ & $63.5 \pm 18.2$ & $51.1 \pm 13.6$ & $60.3 \pm 13.9$ & $60.3 \pm 8.7$ \\
\hline Health related & $65.9 \pm 10.3$ & $68.8 \pm 15.2$ & $59.7 \pm 12.9$ & $66.6 \pm 13.7$ & $66.5 \pm 7.4$ \\
\hline Significance & $.03^{*}$ & $.001 *$ & $.02 *$ & $.01 *$ & $000 *$ \\
\hline \multicolumn{6}{|l|}{ Father education } \\
\hline Uneducated & $60.5 \pm 17.4$ & $59.0 \pm 12.6$ & $49.5 \pm 11.5$ & $58.2 \pm 13.8$ & $56.8 \pm 6.7$ \\
\hline Educated & $64.6 \pm 11.2$ & $66.0 \pm 17.3$ & $55.1 \pm 13.7$ & $63.3 \pm 13.9$ & $62.2 \pm 8.4$ \\
\hline Significance & .10 & .004 & .004 & .01 & $.001 *$ \\
\hline \multicolumn{6}{|l|}{ Mother education } \\
\hline Uneducated & $65.1 \pm 14.7$ & $64.6 \pm 12.5$ & $46.2 \pm 17.7$ & $63.1 \pm 11.5$ & $59.8 \pm 7.4$ \\
\hline Educated & $64.4 \pm 11.3$ & $65.8 \pm 17.5$ & $55.6 \pm 13.1$ & $63.1 \pm 14.1$ & $62.2 \pm 8.5$ \\
\hline Significance & .667 & .097 & $.001^{*}$ & .183 & $.001 *$ \\
\hline
\end{tabular}

$* P<0.05$, significantly different between groups

Table 8-Factors affecting the knowledge of university students regarding food safety in Pakistan. 


\begin{tabular}{|c|c|c|c|c|c|c|c|c|c|c|}
\hline \multirow[t]{2}{*}{ Characteristics } & \multicolumn{2}{|c|}{$\begin{array}{l}\text { Personal hygiene } \\
\text { practices }\end{array}$} & \multicolumn{2}{|c|}{$\begin{array}{l}\text { Causes food-borne } \\
\text { diseases }\end{array}$} & \multicolumn{2}{|c|}{$\begin{array}{l}\text { Symptoms of food-borne } \\
\text { diseases }\end{array}$} & \multicolumn{2}{|c|}{$\begin{array}{l}\text { Food handling } \\
\text { practices }\end{array}$} & \multicolumn{2}{|c|}{$\begin{array}{l}\text { Overall } \\
\text { knowledge }\end{array}$} \\
\hline & AOR & Sig. & AOR & Sig. & AOR & Sig. & AOR & Sig. & AOR & Sig. \\
\hline \multicolumn{11}{|c|}{ Age group (years) } \\
\hline \multicolumn{11}{|l|}{$18-19$} \\
\hline $20-24$ & 1.83 & $0.001 *$ & 1.31 & $0.037^{*}$ & 0.87 & 0.262 & 0.72 & $0.010^{*}$ & 0.90 & 0.432 \\
\hline $25-29$ & 2.05 & $0.017^{*}$ & 2.07 & $0.021 *$ & 2.02 & $0.013^{*}$ & 0.66 & 0.134 & 0.88 & 0.663 \\
\hline$\geq 30$ & 0.34 & $0.040 *$ & 0.79 & 0.635 & 0.31 & $0.023^{*}$ & 0.63 & 0.355 & 0.09 & $0.001 *$ \\
\hline \multicolumn{11}{|l|}{ Gender } \\
\hline \multicolumn{11}{|l|}{ Male } \\
\hline Female & 0.67 & $0.004^{*}$ & 10.27 & $0.064^{*}$ & 1.65 & $0.001 *$ & 1.63 & $0.001 *$ & 1.88 & $0.001 *$ \\
\hline \multicolumn{11}{|l|}{ Education level } \\
\hline \multicolumn{11}{|l|}{ Undergraduate } \\
\hline Postgraduate & 0.62 & $0.004^{*}$ & 1.42 & $0.035 *$ & 0.70 & $0.023^{*}$ & 0.96 & 0.783 & 1.28 & $0.001 *$ \\
\hline \multicolumn{11}{|c|}{ Academic discipline } \\
\hline \multicolumn{11}{|c|}{ Non-health related } \\
\hline Health related & 3.16 & $0.001 *$ & 2.06 & $0.001 *$ & 2.88 & $0.001 *$ & 1.65 & $0.001 *$ & 3.84 & $0.001 *$ \\
\hline \multicolumn{11}{|c|}{ Father's education } \\
\hline \multicolumn{11}{|l|}{ Uneducated } \\
\hline Educated & 2.21 & $0.029 *$ & 3.34 & $0.001 *$ & 1.09 & 0.826 & 10.78 & $0.001 *$ & 3.86 & $0.001 *$ \\
\hline \multicolumn{11}{|c|}{ Mother's education } \\
\hline \multicolumn{11}{|l|}{ Uneducated } \\
\hline Educated & 1.39 & 0.210 & 0.83 & 0.475 & 1.32 & 0.288 & 0.39 & $0.001 *$ & 1.19 & 0.512 \\
\hline
\end{tabular}

$* P<0.05$, significantly different between groups

\section{Supplementary Files}

This is a list of supplementary files associated with this preprint. Click to download.

- Additionalfile1Strobechecklist.doc 